BMJ Open

Diabetes

Research

\& Care

\section{Periodontitis, edentulism and glycemic control in patients with type 2 diabetes: a cross-sectional study}

\author{
Zuila Albuquerque Taboza, ${ }^{1}$ Katia Linhares Costa,${ }^{1}$ Virginia Régia Silveira, ${ }^{2}$ \\ Flavia Aparecida Furlaneto, ${ }^{3}$ Renan Montenegro $\mathrm{Jr}^{4}{ }^{4}$ Stefanie Russell, ${ }^{5}$ \\ Ananda Dasanayake, ${ }^{5}$ Rodrigo O Rego ${ }^{2,5}$
}

To cite: Taboza ZA, Costa KL, Silveira VR, et al. Periodontitis, edentulism and glycemic control in patients with type 2 diabetes: a cross-sectional study. BMJ Open Diab Res Care 2018;6:e000453. doi:10.1136/ bmjdrc-2017-000453

Received 17 July 2017 Revised 26 September 2017 Accepted 23 October 2017

Check for updates

${ }^{1}$ Department of Clinical

Dentistry, Graduate Program in Dentistry, Faculty of Pharmacy, Dentistry and Nursing, Federal University of Ceara, Fortaleza, Ceará, Brazil

${ }^{2}$ Division of Periodontics, Department of Dentistry, School of Dentistry at Sobral, Federal University of Ceara, Sobral, Ceará, Brazil

${ }^{3}$ Department of Surgery and Bucco-Maxillofacial Traumatology and Periodontology, School of Dentistry at Ribeirão Preto, University of São Paulo, Ribeirão Preto, São Paulo, Brazil ${ }^{4}$ Department of Community Health, Faculty of Medicine, Federal University of Ceara, Fortaleza, Ceará, Brazil ${ }^{5}$ Department of Epidemiology \& Health Promotion, New York University College of Dentistry, New York City, New York, USA

Correspondence to Dr Rodrigo 0 Rego; rodrigorego@yahoo.com

\section{ABSTRACT}

Objectives To compare the glycemic control in nonsmoking patients with type 2 diabetes according to their periodontal and dental status.

Research design and methods This cross-sectional study investigated patients previously diagnosed with type 2 diabetes and under antidiabetic medication. Clinical data and fasting blood glucose (FBG) levels were collected from medical and dental records. Patients were divided into three groups according to dental and periodontal diagnosis: no or mild periodontitis (NO/MILD, $n=96$ ), moderate or severe periodontitis (MOD/SEV, $n=74$ ) and edentulous ( $n=141$ ). FBG levels were compared between groups. Logistic regression was also applied to estimate the $\mathrm{OR}$ of presenting hyperglycemia.

Results Edentulous patients had significantly higher FBG levels of $155.7 \pm 70.9($ mean $\pm S D ~ m g / d L)$ than those in the MOD/SEV $(136.6 \pm 33.8)$ and the NO/MILD $(123.1 \pm 36.7)$ groups. Differences between the latter two groups were also significant. Edentulous patients had adjusted ORs of $4.53,4.27$ and 3.95 of having $F B G \geq 126, \geq 150$ and $\geq 180 \mathrm{mg} / \mathrm{dL}$, respectively, in comparison with NO/MILD group. The MOD/SEV group also presented significant odds of having $F B G \geq 126 \mathrm{mg} / \mathrm{dL}(O R=2.66)$ and $\geq 150 \mathrm{mg} / \mathrm{dL}$ $(\mathrm{OR}=2.45)$ than the NO/MILD group.

Conclusions Patients in the MOD/SEV group had worse glycemic control than the ones in the NO/MILD group. However, edentulous patients presented higher glycemic levels than both dentate groups, and also presented with higher odds of having hyperglycemia.

\section{INTRODUCTION}

Diabetes and its complications are one of the most significant and growing chronic health problems in the world. ${ }^{1}$ Severe periodontitis is the sixth most prevalent disease worldwide, with an overall prevalence of $10.8 \%$ and around 743 million people affected. ${ }^{2} \mathrm{~A}$ bidirectional relationship between diabetes and periodontitis has been demonstrated, ${ }^{3}$ which suggests an effect of poor glycemic control on periodontitis, and consequently, tooth loss in more severe cases of the disease. Studies on representative population samples have shown that diabetes can increase the

\section{Significance of this study}

What is already known about this subject?

- Periodontitis has been shown to be associated with increased glycemic levels in type 2 diabetics. We hypothesized that edentulous diabetics would present better glycemic control, since periodontitis cannot be present.

What are the new findings?

- In contrast to what was expected, edentulous patients presented higher glycemic levels than dentate patients with or without periodontitis and also increased odds of presenting hyperglycemia in relation to patients with no or mild periodontitis. The same trend was observed when patients with the most severe forms of periodontitis were compared with the latter group.

How might these results change the focus of research or clinical practice?

- Diabetes screening would be recommended for edentulous patients. The treatment of periodontitis would be important to help reduce glycemic levels and also prevent tooth loss, which can increase the risk for hyperglycemia.

risk for severe periodontal disease by three times. ${ }^{4}$ Elevated glucose levels have also been associated with an increased probability of patients with diabetes presenting periodontitis compared with non-diabetic patients. ${ }^{5}$ On the other hand, periodontitis can affect the glycemic control of type 2 diabetics $^{6}$ and can be an early sign of the disease. ${ }^{7}$

In adults, periodontal disease is the major reason for tooth loss. ${ }^{8}{ }^{9}$ Tooth loss is an important public health problem due to its effects on quality of life, as a result of significant effects on both oral and overall health. ${ }^{10}$ Studies in different populations have demonstrated that diabetes is an important risk factor for tooth loss and edentulism. ${ }^{1-15}$ In a large adult population in Germany, it was reported increased odds (2.19 times) of 
having edentulism in poorly controlled type 2 diabetics in comparison with patients with normal glucose tolerance. ${ }^{11}$ The US National Health and Nutrition Examination Survey data revealed that people with diabetes were 2.25 times more likely to be edentulous than those without diabetes. ${ }^{12}$ Among dentate adults, those with diabetes had a higher number of missing teeth than adults without diabetes, ${ }^{12}$ regardless of race/ethnicity. ${ }^{13}$ On average, adults with diabetes lost approximately twice the number of teeth as adults without diabetes and one of every five cases of edentulism in the USA is linked to diabetes. $^{13}$

Conversely, complete tooth loss has been associated with systemic diseases, such as cardiovascular disease, ${ }^{16} 17$ increased blood pressure, ${ }^{18}$ severe cognitive impairment ${ }^{19}$ and diabetes. ${ }^{2021}$ A cross-sectional study conducted in the US Department of Veteran Affairs revealed that patients with six or fewer teeth had OR of 4.06 times greater for developing type 2 diabetes than those with partial or complete dentitions. ${ }^{20}$ In a large Mexican survey, it was observed that edentulous patients had a 1.82 times greater odds of having diabetes than the dentate patients. ${ }^{21}$ However, since periodontitis adversely affects diabetes outcomes, ${ }^{6}$ there is a lack of information in these studies regarding the presence of periodontitis in dentate patients.

Prospective studies reporting extraction of periodontally compromised teeth were associated with a significant reduction of systemic inflammatory ${ }^{22-24}$ and glycemic markers. ${ }^{25}$ This study included patients with type 2 diabetes with advanced periodontal disease requiring extraction of all affected teeth, and reported a significantly greater reduction of the glycated hemoglobin levels after 3 months in the group which had extractions as a treatment $(1.23 \%)$ compared with the controls $(0.28 \%)$ which did not have any teeth extracted. ${ }^{25}$

Thus, in this context, it is rational to suggest that edentulous patients should present better glycemic control since the absence of teeth may reduce the risk of infection and inflammation associated with periodontal disease. To test this hypothesis, a cross-sectional study was conducted in an adult Brazilian sample. Therefore, the aim of this study was to compare the glycemic control in edentulous and dentate patients with and without periodontitis presenting type 2 diabetes.

\section{MATERIALS AND METHODS}

\section{Data source and study population}

This cross-sectional study included a convenience sample of 311 patients with type 2 diabetes, 141 were completely edentulous and 170 dentate. Patients included in this study were from the urban area of Sobral, Ceara, Brazil. Inclusion criteria were: at least 40 years old, never smokers, use of antidiabetic medication (eg, metformin, glibenclamide or insulin) and registered in the databases of the Brazilian Health Ministry. This last criterion confirmed the medical diagnosis of type 2 diabetes and assures regular audit of medical records. Patients were excluded if inconsistencies or inaccurate information was found in medical records or if they were not edentulous and present less than six teeth.

Demographic data along with antidiabetic medication history and overnight fasting blood glucose (FBG) results were collected by two examiners from medical records of 17 Community Health Centers in the city of Sobral. Examination of FBG was performed at the Public Health Laboratory of Sobral, Brazil, by the colorimetric enzymatic method (Labtest Diagnóstica, Lagoa Santa, MG, Brazil). Once patients with at least six teeth were identified, they were scheduled for subsequent periodontal examination.

A full-mouth periodontal examination was performed in all present teeth excluding third molars with a $15 \mathrm{~mm}$ periodontal probe (UNC-15, Trinity Industria e Comercio, Sao Paulo, SP, Brazil). Plaque index (PI), gingival bleeding index (GBI), probing depth (PD) and gingival recession (GR) were recorded. PI and GBI were assessed dichotomously as presence or absence of visible plaque and gingival bleeding, respectively. ${ }^{26} \mathrm{PD}$ (measured from the gingival margin to the bottom of the pocket) was measured in six sites per tooth (mesiobuccal, buccal, distobuccal, mesiolingual, lingual, distolingual). GR (measured from the cementoenamel junction to the gingival margin) was measured in sites where the gingival margin was located apical to the cementum-enamel junction. Clinical attachment loss (CAL) was calculated for these sites as the sum of PD and GR for each site. One examiner, previously calibrated, performed all examinations. Intraclass correlation coefficient was applied to evaluate intraexaminer reproducibility, with a value of 0.93 for PD.

Data were collected between May and December 2012. The Ethics Committees of the Federal University of Ceara and the State University of the Acarau Valley, Brazil, approved the study protocol. For this study, a completed Strengthening the Reporting of Observational Studies in Epidemiology checklist is provided as a online supplementary file.

\section{Study power}

The ideal sample size to ensure adequate power for this study was calculated considering data previously published regarding comparisons between controlled and poorly controlled dentate patients with type 2 diabetes. ${ }^{427} 28$ It was estimated that $170-210$ dentate patients would be needed to provide $80 \%$ power with $\alpha=0.05$. Then, a convenient sample of 141 edentulous patients attending the public health system of the same community was recruited. The power analysis was recalculated using $\mathrm{G}^{*}$ Power V.3.0.5 ( $\mathrm{G} *$ Power, Heinrich-Heine University, Dusseldorf, Germany) and it was estimated that the current sample, with $\alpha=0.05$, yields 98\% power to detect significant FBG level differences between groups. 


\section{Study variables}

The primary outcome of the study was the influence of tooth loss and periodontitis on FBG levels. Hyperglycemia was considered if a patient presented $\mathrm{FBG} \geq 126 \mathrm{mg}$ / dL. ${ }^{29}$ Presence of periodontitis was diagnosed following the Centers for Disease Control and Prevention and the American Academy of Periodontology case definitions. ${ }^{30}$ Severe periodontitis was defined as having $\geq 2$ interproximal sites with CAL $\geq 6 \mathrm{~mm}$ (not on the same tooth) and one or more interproximal site(s) with PD $\geq 5 \mathrm{~mm}$. Moderate periodontitis was defined as two or more interproximal sites with $\geq 4 \mathrm{~mm}$ CAL (not on the same tooth) or two or more interproximal sites with $\mathrm{PD} \geq 5 \mathrm{~mm}$, also not on the same tooth. The diagnosis of no or mild periodontitis (NO/MILD) was assigned to patients who did not qualify as having moderate or severe periodontitis (MOD/SEV). Then, the patients were divided into three groups: NO/MILD, MOD/SEV and Edentulous.

\section{Statistical analysis}

Comparison of age and FBG between the groups was made by the one-way analysis of variance. The independent samples t-test was used to compare the clinical periodontal parameters PI, GBI, PD, tooth count and FBG among the dentate groups (MOD/SEV vs NO/ MILD). Gender as well as antidiabetic medications was compared between groups by the $\mathrm{X}^{2}$ test.

Multivariate linear regression analysis was also used to assess the FBG levels among the three groups. The models were adjusted for age, gender and number of medications taken. Univariate and multivariate binary logistic regression and OR with $95 \%$ CIs were also applied to estimate the odds of presenting hyperglycemia according to periodontal status and edentulism. To account for severity of hyperglycemia, glycemic control was stratified using FBG cut-off points of 126, 150 and $180 \mathrm{mg} / \mathrm{dL}$. The logistic regression was adjusted for the parameters, which presented statistically significant difference on the linear model.

A difference of $\mathrm{p}<0.05$ was considered statistically significant. The data analysis was performed using SPSS V.23 (SPSS, IBM) and SAS V.9.4 (SAS Institute).

\section{RESULTS}

The sample included 311 patients who were divided into three groups according to the presence of teeth and periodontal disease severity. Data on age, gender, FBG, clinical condition and medications are presented in table 1. The mean age of patients in the edentulous group was significantly higher compared with the other two groups, but not between the two dentate groups. FBG levels were significantly different between all groups. Periodontal clinical parameters PI, GBI and PD were significantly different between dentate groups.

There were no significant differences between groups regarding medications use (table 1 ). Most of the patients included in each group used only one of the antidiabetic medications. Only a small percentage of them used all three medications. According to the multivariate analysis, $13.1 \%$ of the variations observed in FBG levels were a result of age, periodontal status and number of medications. Gender did not affect these results (table 2).

Table 3 presents univariate and multivariable logistic regression models. The ORs of having FBG of $126 \mathrm{mg} / \mathrm{dL}$ were 2.47 for patients presenting moderate to severe periodontitis, and 2.42 for edentulous, when compared with those presenting no or mild periodontitis. After adjusting for age and number of antidiabetic medications, it was observed ORs of 3.08 and 4.53, respectively. The same trend was observed for the other two cut-offs; however, there was a lack of association between the two dentate groups at the $180 \mathrm{mg} / \mathrm{dL}$ cut-off.

\section{CONCLUSIONS}

This study was undertaken with the idea that among type 2 diabetics, the periodontally healthy ones present better glycemic control than those presenting periodontitis. Hypothetically, glucose levels would improve in completely edentulous patients with diabetes, since they cannot develop periodontal disease. According to the American Diabetes Association (2016), FBG cut-off levels for diabetics are equal or greater than $126 \mathrm{mg} / \mathrm{dL} .^{29}$ In the present study, even under antidiabetic medication, patients with moderate to severe periodontitis and edentulism presented, on average, glucose levels above the cut-off when compared with patients presenting no or mild periodontitis. The comparison between the two dentate groups showed statistically significant differences in FBG levels. Patients in both groups presented a similar number of teeth, but PI, GBI and PD were significantly higher in patients with diabetes with moderate to severe periodontitis. After adjusting for age and number of medications taken, these patients presented ORs of 3.08 and 2.77 in relation to no or mild periodontitis for the FBG cut-offs of 126 and $150 \mathrm{mg} / \mathrm{dL}$, respectively. These results were statistically significant and clinically relevant since with an increase in glycemic levels there is an increase in the risk for more diabetes complications. ${ }^{31}$ Similar findings have been reported in other observational studies and demonstrate that glycemic control is worse in patients with more severe forms of periodontitis compared with those without periodontitis or even those with milder forms of the disease. This suggests that periodontal disease adversely affects glycemic control and diabetes complications. ${ }^{63}$ Another important topic regarding this is that periodontitis may be an early sign of diabetes. ${ }^{7}$

However, patients with edentulism presented higher glycemic levels than the ones with the most severe forms of periodontitis and also increased odds of having hyperglycemia in comparison with the healthier group. The studies evaluating the association between tooth loss, edentulism and diabetes did not take into account the presence of periodontitis among dentate patients ${ }^{20} 21$ 
Table 1 Characteristics of the study population

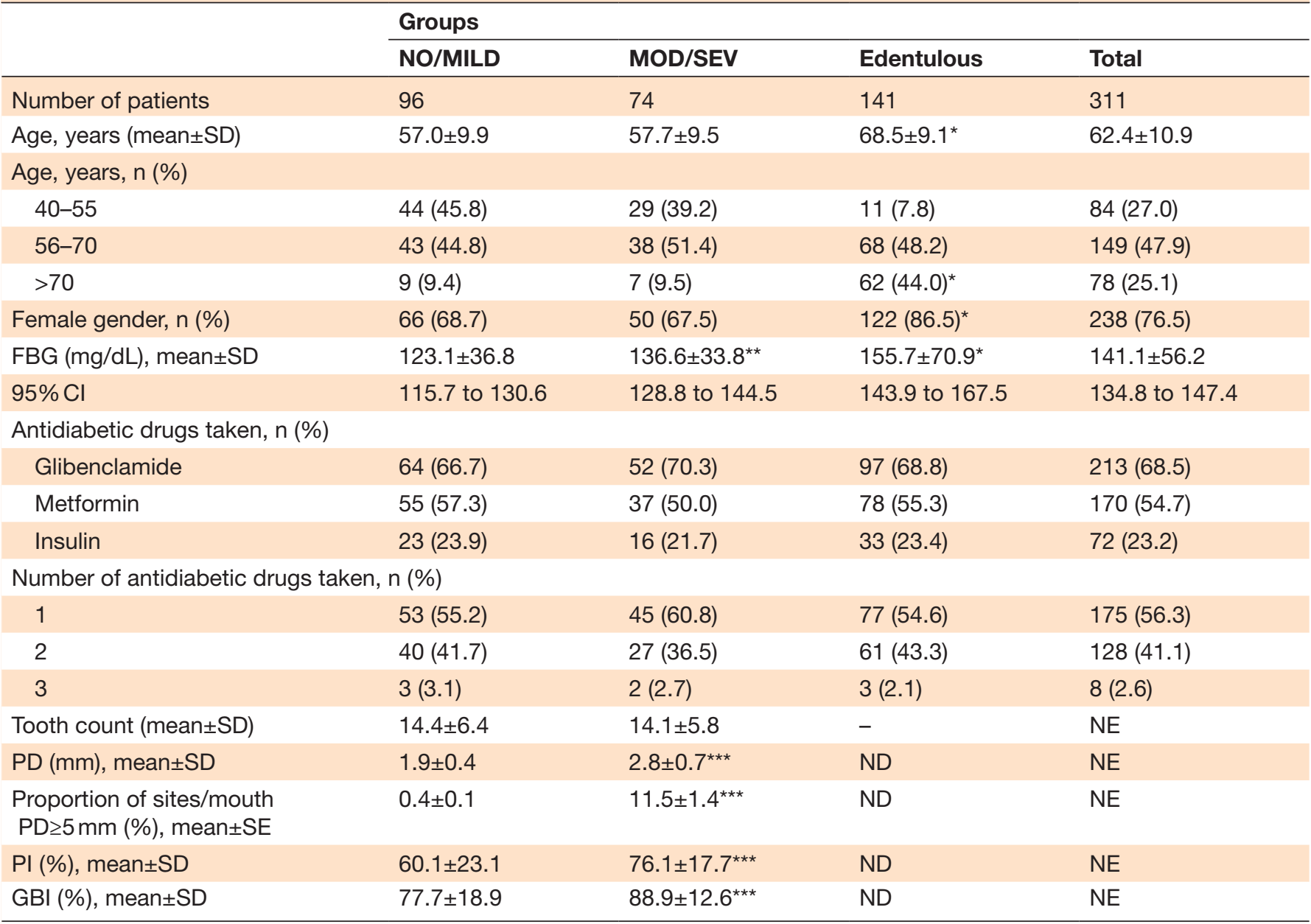

${ }^{*} \mathrm{P}<0.001$, different from MOD/SEV and NO/MILD; ${ }^{* *} \mathrm{P}=0.01$, different from NO/MILD; ${ }^{* *} P<0.001$, different from NO/MILD.

FBG, fasting blood glucose; GBI, gingival bleeding index; MOD/SEV, moderate or severe periodontitis; ND, no data; NE, not estimated; NO/ MILD, no or mild periodontitis; PD, probing depth; PI, plaque index.

or were carried out using the diabetes diagnosis or the glycemic control as the independent variable. ${ }^{11-15}$ Based on large epidemiological studies from the $\mathrm{USA}^{12}$ and Germany, ${ }^{11}$ diabetics were 2.25 and 2.19 times more likely to be edentulous than were those without diabetes,

Table 2 Linear regression analysis models evaluating the response to FBG adjusted for multiple variables

\begin{tabular}{lrcc}
\hline Variable & Model 1 & Model 2 & Model 3 \\
\hline $\begin{array}{l}\text { Periodontal status/ } \\
\text { edentulism }\end{array}$ & $\mathrm{P}<0.001$ & $\mathrm{P}<0.001$ & $\mathrm{P}<0.001$ \\
Age & $\mathrm{P}<0.001$ & $\mathrm{P}<0.001$ & $\mathrm{P}<0.001$ \\
$\begin{array}{l}\text { Number of antidiabetic } \\
\text { drugs taken }\end{array}$ & $\mathrm{P}<0.001$ & $\mathrm{P}<0.001$ & $\mathrm{NE}$ \\
Gender & $\mathrm{P}=0.240$ & $\mathrm{NE}$ & $\mathrm{NE}$ \\
$\mathrm{R}^{2}$ & 0.145 & & \\
$\mathrm{R}^{2}$ adjusted & 0.131 & & \\
$\mathrm{~F}$ & 10.37 & & \\
$\mathrm{P}$ & $<0.001$ & & \\
\hline
\end{tabular}

FBG, fasting blood glucose; NE, not estimated. respectively. A representative sample of the American population has shown that adults with diabetes lost more teeth compared with those without diabetes, thus demonstrating that diabetes is an important risk factor for tooth loss. Adults with diabetes lost twice more teeth on average than patients without diabetes, increasing from 1.7 times, between 1971 and 1975, to 2.1 times between 2011 and 2012, independent of race/ethnicity. ${ }^{13}$ A study including 35000 dentate adult men evaluated the association between type 2 diabetes and the incidence of periodontal disease and tooth loss in a 20-year period. ${ }^{14}$ The authors observed that type 2 diabetes was associated with a $22 \%$ increase in tooth loss compared with those patients without diabetes. Another study evaluating the association between diabetes and tooth loss in approximately 16.000 Hispanic/Latino adults found that the risk of being edentulous was 2.2 times greater in poorly controlled type 2 diabetics than in patients without diabetes. $^{15}$

In the present study, the mean age of the edentulous group was 68.5 years, and the NO/MILD and MOD/ SEV groups were 57.0 and 57.7, respectively. It has been 
Table 3 Bivariate and multivariate analyses comparing participants' periodontal status and glycemic control at different cutoffs on FBG levels

\begin{tabular}{|c|c|c|c|c|c|}
\hline \multirow[b]{2}{*}{ Clinical condition } & \multirow[b]{2}{*}{ n (\%) } & \multirow[b]{2}{*}{ n (\%) } & \multirow{2}{*}{$\begin{array}{l}\text { Unadjusted } \\
\text { OR }(95 \% \mathrm{Cl})\end{array}$} & \multirow{2}{*}{$\begin{array}{l}\text { Adjusted }^{*} \\
\text { OR }(95 \% \mathrm{Cl})\end{array}$} & \multirow{2}{*}{$\begin{array}{l}\text { Adjusted† } \\
\text { OR }(95 \% \mathrm{Cl})\end{array}$} \\
\hline & & & & & \\
\hline & $\geq 126 \mathrm{mg} / \mathrm{dL}$ & $<126 \mathrm{mg} / \mathrm{dL}$ & & & \\
\hline NO/MILD & $37(38.5)$ & $59(61.5)$ & Referent & Referent & Referent \\
\hline MOD/SEV & $45(60.8)$ & $29(39.2)$ & 2.47 (1.33 to 4.60$)$ & 2.66 (1.40 to 5.04$)$ & 3.08 (1.6 to 6.0$)$ \\
\hline \multirow[t]{2}{*}{ Edentulous } & $85(60.3)$ & $56(39.7)$ & 2.42 (1.42 to 4.11$)$ & 4.33 (2.27 to 8.24$)$ & 4.53 (2.3 to 8.8 ) \\
\hline & $\geq 150 \mathrm{mg} / \mathrm{dL}$ & $<150 \mathrm{mg} / \mathrm{dL}$ & & & \\
\hline NO/MILD & $22(22.9)$ & $74(77.1)$ & Referent & Referent & Referent \\
\hline MOD/SEV & $30(40.5)$ & $44(59.5)$ & 2.29 (1.18 to 4.46$)$ & 2.45 (1.24 to 4.84$)$ & 2.77 (1.36 to 5.62 ) \\
\hline \multirow[t]{2}{*}{ Edentulous } & $57(40.4)$ & $84(59.6)$ & 2.28 (1.27 to 4.08$)$ & 4.53 (2.03 to 8.11$)$ & 4.27 (2.08 to 8.75 ) \\
\hline & $\geq 180 \mathrm{mg} / \mathrm{dL}$ & $<180 \mathrm{mg} / \mathrm{dL}$ & & & \\
\hline NO/MILD & $12(12.5)$ & $84(87.5)$ & Referent & Referent & Referent \\
\hline MOD/SEV & $10(13.5)$ & $64(86.5)$ & 1.09 (0.45 to 2.69$)$ & 1.13 (0.45 to 2.83$)$ & 1.19 (0.47 to 2.99$)$ \\
\hline Edentulous & $34(24.1)$ & $107(75.9)$ & 2.45 (1.08 to 4.56$)$ & 3.87 (1.67 to 8.97$)$ & 3.95 (1.68 to 9.28 ) \\
\hline
\end{tabular}

Bold text indicates a statistically significant association.

${ }^{*}$ Adjusted for age.

$\dagger$ Adjusted for age and number of antidiabetic medications taken.

FBG, fasting blood glucose; MOD/SEV, moderate or severe periodontitis; NO/MILD, no or mild periodontitis.

demonstrated that the prevalence of periodontal disease increases with age ${ }^{33}$ and elevated glucose levels may be more difficult to be controlled due to an increase in insulin resistance. ${ }^{34}$ Even with the use of antidiabetic agents, higher glucose levels in older patients can be due to increased insulin resistance observed in this age group. However, after adjusting for age, the results remained statistically significant and clinically relevant. It can be hypothesized that older adults may have presented with diabetes for a much longer period compared with the younger age groups. Although diabetes duration was not evaluated in this study, it is known that the longer the diabetes duration the worst are the complications associated with it. ${ }^{35} 36$ Thus, older patients may present with greater duration of the disease and consequently have also been exposed to periodontopathogens for a longer period, presenting signs of periodontal disease, and a faster disease progression leading to tooth loss. Nonetheless, the causes of tooth loss were not investigated in this study. It can also be hypothesized that patients with diabetes who are negligent with their overall health could also be negligent with their oral health, and present with more complications associated with diabetes. ${ }^{3738}$ Another factor that could have contributed to the finding of edentulism in older groups is that until the late 1980s the dental service offered by the public health system in Brazil was, in the vast majority, tooth extraction.

A very important aspect of this population was its characterization. All individuals used the Brazilian healthcare system, were diabetic and used some type of antidiabetic medication to control the disease. The patients were residents of the urban area of the same city and it was assumed that everyone had the same eating habits, living conditions, overall quality of life and socioeconomic status. ${ }^{32}$ Another important topic was the fact that they were all non-smokers. Smoking is a risk as well as a detrimental factor for both diabetes and periodontal disease. ${ }^{39}$ Since the study population consisted of non-smokers, it is possible to infer that smoking did not influence the onset and course of both conditions, which is highly recommended when evaluating the relationship between systemic diseases and their risk factors. ${ }^{40}$

It is important to keep in mind some of the limitations of the present study. One was the evaluation of glycemic control by FBG, which is common in low/middle-income countries like Brazil, where this research was carried out. ${ }^{29}$ Despite the fact that glycated hemoglobin (HbAlc) is considered the gold standard for being the most accurate method, good correlation between FBG and HbA1c has been demonstrated. ${ }^{41}$ The FBG threshold of $150 \mathrm{mg}$ / $\mathrm{dL}$ would be equivalent to HbAlc levels around 7\% (ie, $6.9 \%)$, the suggested target for diabetes control. ${ }^{42}$ After adjustments, the odds of presenting $\mathrm{FBG} \geq 150 \mathrm{mg} / \mathrm{dL}$ on edentulous and moderate to severe periodontitis groups in relation to the NO/MILD group were 4.27 and 2.77, respectively. Thus, the increased odds presented by the edentulous patients and also by patients with moderate to severe periodontitis may lead to relevant negative impacts on the systemic health due to the higher risk for major diabetes complications such as nephropathy and micro/macrovascular outcomes. ${ }^{31} 4344$

The present study is a cross-sectional evaluation and the associations are made according to previous observations in the study population. This study design does not account for temporality. Therefore, it cannot be determined if the diabetes led to the tooth loss or if the 
observed tooth loss contributed to the poor glycemic control of the edentulous group. Since these patients were not longitudinally followed, other factors associated with diabetes and glucose control, such as level of physical activity, weight, body mass index and diet, also could not be studied. Another possible limitation of this study is the lack of information on the use of prosthesis. The chewing ability of individuals with complete dentures is impaired due to tooth loss, and this can lead to a reduced intake of fruits and vegetables. ${ }^{45}$ Complete denture wearers have been reported to eat a diet low in nutrients, abundantly found in fruits and vegetables, compared with those with natural teeth. ${ }^{46}$ Besides this, it has been reported that the biofilm formed on dentures can harbor bacteria, fungi and yeast, which can trigger an inflammatory response in the oral tissues. ${ }^{47}$ Thus, this lack of information did not allow us to draw a plausible relationship between denture hygiene and a possible metabolic dysregulation that would be observed in the edentulous group.

It can be concluded that moderate and severe periodontitis are associated with higher FBG levels compared with milder forms of the disease or no periodontitis. Edentulous patients presented worse glycemic control when compared with patients with teeth, independent of periodontal status. These findings emphasize the need for improved oral healthcare in patients with type 2 diabetes. They also serve as a warning that the treatment of periodontitis would be important to help reduce glucose levels and also prevent tooth loss, which can increase the risk for hyperglycemia. Diabetes screening would be recommended for edentulous patients. Further longitudinal studies, controlling for confounding factors and possibly for periodontitis inflammatory markers, are necessary in order to clarify the relationship between type 2 diabetes, periodontitis and tooth loss.

Contributors ROR conceptualized the study and wrote the manuscript. AD conducted the data analysis and aided in writing the paper. ZAT collected the data and contributed to writing the manuscript. RMJr and SR contributed to writing, editing and revising the manuscript. FAF and VRS reviewed and edited the manuscript. KLC collected the data and reviewed the manuscript. All authors gave final approval and agree to be accountable for all aspects of the work.

Funding This study was sponsored by the Coordination for the Improvement of Higher Education Personnel (CAPES), Ministry of Education, Brazil (Grants: Estagio Senior 99999.002461/2015-03 and PROCAD NF 2313/2008), and Ceara State Research Foundation (FUNCAP), Ceara State Department of Science and Technology, Brazil (Grant 266.0100/09).

Competing interests None declared.

Patient consent Obtained.

Ethics approval The Ethics Committees of the Federal University of Ceara and the State University of the Acarau Valley, Brazil.

Provenance and peer review Not commissioned; externally peer reviewed. Data sharing statement No additional data are available.

Open Access This is an Open Access article distributed in accordance with the Creative Commons Attribution Non Commercial (CC BY-NC 4.0) license, which permits others to distribute, remix, adapt, build upon this work non-commercially, and license their derivative works on different terms, provided the original work is properly cited and the use is non-commercial. See: http://creativecommons.org/ licenses/by-nc/4.0/ (c) Article author(s) (or their employer(s) unless otherwise stated in the text of the article) 2018. All rights reserved. No commercial use is permitted unless otherwise expressly granted.

\section{REFERENCES}

1. International Federation of Diabetes. The global picture. In: International Diabetes Federation Diabetes Atlas, 2015:47-66.

2. Marcenes W, Kassebaum NJ, Bernabé E, et al. Global burden of oral conditions in 1990-2010: a systematic analysis. J Dent Res 2013;92:592-7.

3. Taylor JJ, Preshaw PM, Lalla E. A review of the evidence for pathogenic mechanisms that may link periodontitis and diabetes. J Clin Periodontol 2013;40(Suppl 14):S113-34.

4. Tsai C, Hayes C, Taylor GW. Glycemic control of type 2 diabetes and severe periodontal disease in the US adult population. Community Dent Oral Epidemiol 2002;30:182-92.

5. Garcia D, Tarima S, Okunseri C. Periodontitis and glycemic control in diabetes: NHANES 2009 to 2012. J Periodontol 2015;86:499-506.

6. Borgnakke WS, Ylöstalo PV, Taylor GW, et al. Effect of periodontal disease on diabetes: systematic review of epidemiologic observational evidence. J Clin Periodontol 2013;40(Suppl 14):S135-52.

7. Teeuw WJ, Kosho MX, Poland DC, et al. Periodontitis as a possible early sign of diabetes mellitus. BMJ Open Diabetes Res Care 2017;5:e000326.

8. Hull PS, Worthington HV, Clerehugh V, et al. The reasons for tooth extractions in adults and their validation. $J$ Dent 1997;25:233-7.

9. Aida J, Ando Y, Akhter R, et al. Reasons for permanent tooth extractions in Japan. J Epidemiol 2006;16:214-9.

10. Gerritsen AE, Allen PF, Witter DJ, et al. Tooth loss and oral healthrelated quality of life: a systematic review and meta-analysis. Health Qual Life Outcomes 2010;8:126.

11. Kowall B, Holtfreter B, Völzke H, et al. Pre-diabetes and wellcontrolled diabetes are not associated with periodontal disease: the SHIP Trend Study. J Clin Periodontol 2015;42:422-30.

12. Patel MH, Kumar JV, Moss ME. Diabetes and tooth loss: an analysis of data from the National Health and Nutrition Examination Survey, 2003-2004. J Am Dent Assoc 2013;144:478-85.

13. Luo H, Pan W, Sloan F, et al. Forty-year trends in tooth loss among american adults with and without diabetes mellitus: an age-periodcohort analysis. Prev Chronic Dis 2015;12:E211.

14. Jimenez M, Hu FB, Marino M, et al. Type 2 diabetes mellitus and 20 year incidence of periodontitis and tooth loss. Diabetes Res Clin Pract 2012;98:494-500.

15. Greenblatt AP, Salazar CR, Northridge ME, et al. Association of diabetes with tooth loss in Hispanic/Latino adults: findings from the Hispanic Community Health Study/Study of Latinos. BMJ Open Diabetes Res Care 2016;4:e000211.

16. Desvarieux M, Demmer RT, Rundek T, et al. Relationship between periodontal disease, tooth loss, and carotid artery plaque: the Oral Infections and Vascular Disease Epidemiology Study (INVEST). Stroke 2003;34:2120-5.

17. LaMonte MJ, Genco RJ, Hovey KM, et al. History of periodontitis diagnosis and edentulism as predictors of cardiovascular disease, stroke, and mortality in postmenopausal women. J Am Heart Assoc 2017:6:e004518.

18. Peres MA, Tsakos G, Barbato PR, et al. Tooth loss is associated with increased blood pressure in adults--a multidisciplinary populationbased study. J Clin Periodontol 2012;39:824-33.

19. Peres MA, Bastos JL, Watt RG, et al. Tooth loss is associated with severe cognitive impairment among older people: findings from a population-based study in Brazil. Aging Ment Health 2015;19:876-84.

20. Cleary TJ, Hutton JE. An assessment of the association between functional edentulism, obesity, and NIDDM. Diabetes Care 1995;18:1007-9.

21. Medina-Solís CE, Pérez-Núñez R, Maupomé G, et al. Edentulism among Mexican adults aged 35 years and older and associated factors. Am J Public Health 2006:96:1578-81.

22. Fokkema SJ, Loos BG, Hart AA, et al. Long-term effect of fullmouth tooth extraction on the responsiveness of peripheral blood monocytes. J Clin Periodontol 2003;30:756-60.

23. Taylor BA, Tofler GH, Carey HM, et al. Full-mouth tooth extraction lowers systemic inflammatory and thrombotic markers of cardiovascular risk. J Dent Res 2006;85:74-8.

24. Vuletic S, Taylor BA, Tofler GH, et al. SAA and PLTP activity in plasma of periodontal patients before and after full-mouth tooth extraction. Oral Dis 2008;14:514-9. 
25. Khader YS, Al Habashneh R, Al Malalheh M, et al. The effect of full-mouth tooth extraction on glycemic control among patients with type 2 diabetes requiring extraction of all remaining teeth: a randomized clinical trial. J Periodontal Res 2010;45:741-7.

26. Ainamo J, Bay I. Problems and proposals for recording gingivitis and plaque. Int Dent J 1975;25:229-35

27. Soskolne WA, Klinger A. The relationship between periodontal diseases and diabetes: an overview. Ann Periodontol 2001;6:91-8.

28. Jansson $\mathrm{H}$, Lindholm $\mathrm{E}$, Lindh $\mathrm{C}$, et al. Type 2 diabetes and risk for periodontal disease: a role for dental health awareness. J Clin Periodontol 2006;33:408-14.

29. American Diabetes Association. Classification and diagnosis of diabetes. Diabetes Care 2016;39(Suppl 1):S13-22.

30. Eke PI, Page RC, Wei L, et al. Update of the case definitions for population-based surveillance of periodontitis. J Periodontol 2012;83:1449-54.

31. Stratton IM, Adler Al, Neil HA, et al. Association of glycaemia with macrovascular and microvascular complications of type 2 diabetes (UKPDS 35): prospective observational study. BMJ 2000;321:405-12.

32. Costa KL, Taboza ZA, Angelino GB, et al. Influence of Periodontal Disease on Changes of Glycated Hemoglobin Levels in Patients With Type 2 Diabetes Mellitus: A Retrospective Cohort Study. $J$ Periodontol 2017;88:17-25.

33. Eke PI, Dye BA, Wei L, et al. Update on prevalence of periodontitis in adults in the United States: NHANES 2009 to 2012. J Periodontol 2015;86:611-22.

34. Barbagallo M, Resnick LM, Dominguez LJ, et al. Diabetes mellitus, hypertension and ageing: the ionic hypothesis of ageing and cardiovascular-metabolic diseases. Diabetes Metab 1997;23:281-94.

35. Huang ES, Laiteerapong N, Liu JY, et al. Rates of complications and mortality in older patients with diabetes mellitus: the diabetes and aging study. JAMA Intern Med 2014;174:251-8.

36. Zoungas S, Woodward M, Li Q, et al. Impact of age, age at diagnosis and duration of diabetes on the risk of macrovascular and microvascular complications and death in type 2 diabetes. Diabetologia 2014;57:2465-74.

37. Tapp RJ, Tikellis G, Wong TY, et al. Longitudinal association of glucose metabolism with retinopathy: results from the Australian Diabetes Obesity and Lifestyle (AusDiab) study. Diabetes Care 2008;31:1349-54.

38. Eldarrat $\mathrm{AH}$. Awareness and attitude of diabetic patients about their increased risk for oral diseases. Oral Health Prev Dent 2011;9:235-41.

39. Yeh HC, Duncan BB, Schmidt MI, et al. Smoking, smoking cessation, and risk for type 2 diabetes mellitus: a cohort study. Ann Intern Med 2010;152:10-17.

40. Spiekerman CF, Hujoel PP, DeRouen TA. Bias induced by selfreported smoking on periodontitis-systemic disease associations. $J$ Dent Res 2003;82:345-9.

41. Rohlfing CL, Wiedmeyer HM, Little RR, et al. Defining the relationship between plasma glucose and $\mathrm{HbA}(1 \mathrm{c})$ : analysis of glucose profiles and $\mathrm{HbA}(1 \mathrm{c})$ in the Diabetes Control and Complications Trial. Diabetes Care 2002;25:275-8.

42. American Diabetes Association. A1c and eAG. http://www.diabetes. org/living-withdiabetes/treatment-and-care/blood-glucose-control/ a1c/ (accessed 6 jan 2017).

43. Holman RR, Paul SK, Bethel MA, et al. 10-year follow-up of intensive glucose control in type 2 diabetes. N Engl J Med 2008;359:1577-89.

44. American Diabetes Association. Implications of the United Kingdom prospective diabetes study. Diabetes Care 2002;25(suppl 1):s28-32.

45. Zhu Y, Hollis JH. Associations between the number of natural teeth and metabolic syndrome in adults. J Clin Periodontol 2015;42:113-20.

46. Nowjack-Raymer RE, Sheiham A. Association of edentulism and diet and nutrition in US adults. J Dent Res 2003;82:123-6.

47. Barros SP, Suruki R, Loewy ZG, et al. A cohort study of the impact of tooth loss and periodontal disease on respiratory events among COPD subjects: modulatory role of systemic biomarkers of inflammation. PLoS One 2013;8:e68592. 